\title{
What should we hope to achieve when treating rheumatoid arthritis?*
}

\author{
D L SCOTT, ${ }^{1}$ T D SPECTOR, ${ }^{1}$ T PULLAR, ${ }^{2}$ AND B MCCONKEY
}

From the 'Department of Rheumatology, St Bartholomew's and Homerton Hospitals, London; the ${ }^{2}$ Department of Clinical Pharmacology, The General Infirmary, Leeds; and ${ }^{3}$ Priory Hospital, Edgbaston, Birmingham

There is no doubt that current antirheumatic drugs are better than placebos in prospective placebo controlled clinical trials in rheumatoid arthritis (RA). This has been shown for non-steroidal antiinflammatory drugs and slow acting antirheumatic drugs. ${ }^{1}$ Studies of the natural history of treated RA in patients seen in specialist clinics and followed up for $10-20$ years $^{2-4}$ show, however, that the disease causes excessive mortality and significant morbidity.

What is the best treatment plan? In some clinical situations it is easy to evaluate the best approaches to management; for example, patients with a serious head injury either live or die, ${ }^{56}$ and treatment policies which influence outcome can be developed using this. The ability to divide patients with RA into therapeutic successes or failures is an equally important prerequisite for evaluating rheumatological treatment. A classification of response to treatment is useful both in assessment within clinical trials and in individual patient management.

A consensus meeting was held at St Bartholomew's Hospital to consider which measures should be used and how much weight should be attached to them. The meeting involved 15 rheumatological workers from nine centres with special interests in the area of disease assessment and took the form of an extended round table discussion to achieve a reconciled assessment of opinion: a true

Accepted for publication 21 July 1988.

Correspondence to Dr D L Scott, Department of Rheumatology, St Bartholomew's Hospital, West Smithfield, London EC1A 7BE.

*Based on a consensus meeting at St Bartholomew's Hospital attended by $\mathrm{H}$ A Bird (Leeds), H Capell (Glasgow), J E Dacre (London), P T Dawes (Stoke), J S Dixon (Leeds), D Doyle (London), A Greenwood (London), E C Huskisson (London), B McConkey (Birmingham), A J Popert (Droitwich), T Pullar (Leeds), D L Scott (London), T Spector (London), D Symmons (Birmingham), P Thompson (London). group consensus. Three questions were examined. $\bar{z}$ How good are the present measures of response to antirheumatic drugs? What should we be measur- $\stackrel{\rho}{\supset}$ ing? Which directions offer the best opportunities for future investigations?

\section{Types of measure}

A wide variety of different measures are used in RA. Very few are completely valueless; none is $\frac{\mathscr{Q}}{\Phi}$ ideal. Patients with RA often consider pain to be $\stackrel{\varrho}{a}$ their predominant symptom, ${ }^{7}$ but few patients with $\overrightarrow{\overrightarrow{0}}$ RA followed up in specialist units manage with 3 analgesics alone. Studies to evaluate the main antirheumatic drugs (non-steroidal anti-inflammatory drugs or slow acting antirheumatic drugs) use a mixture of clinical and laboratory variables to assess disease activity (Table 1). Radiological progression of joint damage is often put forward as the predominant measure of effective treatment ${ }^{89}$ though there is some dissent from this view. ${ }^{10} 11$ Functional indices such as the Health Assessment Questionnaire (HAQ) are increasingly used. ${ }^{12} \frac{D}{0}$ Death is the final arbiter of disease; RA leads to increased mortality, ${ }^{13}$ though this is only observable $\mathrm{N}$ over a long time period.

With such a variety of measures, which should be relied upon? How do the different measures relate? Additive indices of disease activity have received attention in recent years, including the Mallya and Mace index ${ }^{14}$ and the Lansbury index. ${ }^{15} \mathrm{~A}$ similar $\stackrel{\odot}{\mathscr{}}$ disease activity index has been derived in Stoke. ${ }^{16} \stackrel{?}{?}$ Such multidimensional indexes have been used in ${ }_{0}^{\circ}$ several studies. Although they seem a good $\overrightarrow{\mathbb{D}}$ approach, they lack a scientific basis, they contain $\frac{\rho}{\mathbb{D}}$ several independent variables, and they have not $\stackrel{\circ}{\circ}$ been subjected to rigorous validation. To derive valuable and lasting clinical data rheumatologists $\delta$ 
What should we hope to achieve when treating rheumatoid arthritis?

Table 1 Conventional clinical and laboratory measures used to assess disease activity in rheumatoid arthritis

\begin{tabular}{|c|c|c|}
\hline $\begin{array}{l}\text { Type of } \\
\text { measure }\end{array}$ & Variable & Comment on use \\
\hline Clinical & $\begin{array}{l}\text { Duration of morning } \\
\text { stiffness } \\
\text { Joint pain } \\
\text { Articular index } \\
\text { PIP* joint size } \\
\text { Grip strength } \\
\text { Number of nodules } \\
\text { Walking time }\end{array}$ & $\begin{array}{l}\text { Difficult to measure } \\
\text { accurately } \\
\text { Interpatient variability } \\
\text { Interpatient variability } \\
\text { Little change } \\
\text { Reflects function } \\
\text { Too little change } \\
\text { Not standardised }\end{array}$ \\
\hline Laboratory & $\begin{array}{l}\text { ESR }^{*} \\
\text { Plasma viscosity } \\
\text { C reactive protein } \\
\text { Haemoglobin } \\
\text { Platelets } \\
\text { Alkaline phosphate } \\
\text { Rheumatoid factor titre } \\
\text { Antinuclear antibody } \\
\text { titre } \\
\text { Immunoglobulin G, A, } \\
\text { and M concentrations } \\
\text { Complement C3 } \\
\text { concentration } \\
\text { Histidine } \\
\text { Thiol concentration }\end{array}$ & $\begin{array}{l}\text { Widely used but wide } \\
\text { range } \\
\text { Available at few centres } \\
\text { Available at few centres } \\
\text { Little change } \\
\text { Quite a good measure } \\
\text { Little change } \\
\text { Conflicting data on change } \\
\text { Conflicting data on change } \\
\text { Little change } \\
\text { Little change } \\
\text { Available at few centres } \\
\text { Available at few centres }\end{array}$ \\
\hline
\end{tabular}

${ }^{*} \mathrm{PIP}=$ proximal interphalangeal; $\mathrm{ESR}=$ erythrocyte sedimentation rate.

must turn away from pseudoscientific approaches and tackle these questions in a more direct manner. Other sorts of complex index exist which are more acceptable. The best known is the HAQ, which has been modified for use in the United Kingdom. ${ }^{17}$

The group's overall view, reached with considerable, almost surprising, unanimity, was that there are five categories of measure relevant to the outcome of RA (Table 2). These are relevant over different time scales-the short term including time periods of one or two years and the long term of one or two decades. No measure should be considered entirely in isolation, but they may be relatively independent of each other. The importance of mortality, severe morbidity, and functional impairment outweighs clinical and laboratory indices of disease activity.

\section{Responses to slow acting antirheumatic drugs}

Analgesics and non-steroidal anti-inflammatory drugs have only short term symptom relieving effects and are not relevant to the determination of disease outcome except in a negative sensetoxicity. By contrast, slow acting antirheumatic drugs, such as gold and penicillamine, have the potential to influence the course of RA. How should
Table 2 Types of measure in rheumatoid arthritis

\begin{tabular}{ll}
\hline Time course & Type of measure \\
\hline Long term (10-20 years) & $\begin{array}{l}\text { Mortality } \\
\text { Morbidity assessment }\end{array}$ \\
Short and long term & $\begin{array}{l}\text { Functional index } \\
\text { Drug reaction index }\end{array}$ \\
Short term (1-2 years) & $\begin{array}{l}\text { Clinical and laboratory indices } \\
\text { of disease activity }\end{array}$ \\
\hline
\end{tabular}

their effects be measured? One of the synonyms for these drugs is remission inducing drugs. There are validated American Rheumatism Association criteria for remission, ${ }^{18}$ which could be used for assessing the effects of the drugs. Only a few patients with RA treated with slow acting drugs enter prolonged remission, however. Therefore remission by itself is not a very useful tool in judging therapeutic response.

The traditional method of evaluating a slow acting drug in a randomised prospective study is to show a significant improvement in clinical measures, such as joint swelling and tenderness and morning stiffness, and reduction of acute phase reactants, such as $C$ reactive protein and erythrocyte sedimentation rate (ESR). Each clinical and laboratory variable is usually compared separately in patients treated with drugs and controls given a placebo. Examples include the first studies of slow acting drugs such as gold and penicillamine. ${ }^{19} 20$ These showed that treatment is better with a slow acting drug than with placebo, but they gave limited information about the extent of improvement in any given patient. They did not allow for standardisation of response.

The American Rheumatism Association remission criteria can serve as a basis for formulating different response scales. ${ }^{18}$ These criteria consist of six requirements: morning stiffness of 15 minutes or less; no fatigue; no joint pain; no joint tenderness; no soft tissue swelling; and ESR $<30 \mathrm{~mm} / \mathrm{h}$ in women and $<20 \mathrm{~mm} / \mathrm{h}$ in men. They can be modified to determine varying degrees of response. The first step is to abandon those components which cannot be readily measured, such as fatigue. Secondly, joint tenderness and swelling should be considered together as they are often difficult to dissociate. This leaves three clinical and one laboratory variable: morning stiffness; joint pain; joint tenderness/swelling; and ESR. Together they can be used to give a set of response criteria (Table 3). Despite the problems associated with their measurement (outlined in Table 1) these variables were 
Table 3 Response to slow acting antirheumatic drugs

\begin{tabular}{|c|c|c|c|}
\hline \multirow[t]{2}{*}{ Indices } & \multicolumn{3}{|l|}{ Response } \\
\hline & $\begin{array}{l}\text { Complete } \\
\text { (remission) }\end{array}$ & Partial & Poor \\
\hline \multicolumn{4}{|l|}{ Clinical } \\
\hline Pain & None & $\begin{array}{l}\text { Controlled by } \\
\text { symptomatic drug treatment }\end{array}$ & $\begin{array}{l}\text { Uncontrolled } \\
\text { symptomatic } \\
\text { drug treatment }\end{array}$ \\
\hline Swelling/tenderness & None & 1-3 Joints & Over 3 joints \\
\hline Morning stiffness (min) & $<15$ & $<30$ & $>30$ \\
\hline \multicolumn{4}{|l|}{ Laboratory } \\
\hline $\begin{array}{l}\mathrm{ESR} \dagger(\mathrm{mm} / \mathrm{h}) \text { (or plasma viscosity) } \\
\text { or }\end{array}$ & $<30$ & $30-45$ & $>45$ or no fall \\
\hline $\mathrm{C}$ reactive protein $(\mathrm{mg} / \mathrm{l})$ & $<20$ & $20-30$ & $>30$ or no fall \\
\hline
\end{tabular}

${ }^{*}$ Non-steroidal anti-inflammatory drugs or analgesics, or both.

$\dagger \mathrm{ESR}=$ erythrocyte sedimentation rate.

chosen. Plasma viscosity has replaced ESR in some centres and $C$ reactive protein may be preferred by others.

The problem is to define a simple classification for grading response to slow acting antirheumatic drugs in a way which can be used for comparison between different centres. It should also be clinically appropriate and open to subsequent evaluation. There are no solid scientific reasons for preferring one set of values or measures to another. The rationale for using response criteria has to be based on current clinical opinion. For that reason a consensus meeting has a role in determining criteria. The overall view was that response could be categorised as remission (complete response); partial response; and poor response. These categories are relevant in everyday clinical practice and are often the basis on which further treatment is decided. A baseline of four clinical and laboratory variables as a modified definition of remission was taken and preliminary criteria for the intermediate grades of response proposed (Table 3 ). These need validation and may require modification. The point at issue is not so much the precise values given to the different variables, but the general approach to designing criteria for response. Thus the variables should be simple to record and reproducible; have clinical meaning; and be able to show change.

Our choice of variables is similar to that of Dixon et $a .^{21}$ They looked at changes in panels of clinical measures and laboratory variables. Seventy one patients with RA treated with one of five slow acting antirheumatic drugs were followed up for 24 weeks by measuring seven clinical and seven laboratory variables. The results showed that articular index and summated change score were the 'best' clinical measures, while ESR and plasma viscosity were the best laboratory measures. Grip strength and joint size fared badly and could not be recommendedoo Clinical variables improved more rapidly than laboratory measures, but the latter showed the greater change.

\section{Morbidity assessment}

Changes in clinical or laboratory indices have man $\vec{\phi}$ uses, but they do not help directly to define the long term impact of RA on a patient's health. How ca? this be examined? The question is not a new one Fries and others have referred to the 'five Ds' of death, disability, discomfort, drug side effects, an dollars. ${ }^{22}$ The perceived problems of using clinicat measures have led to the introduction of functionat assessments. The best known of these are HAQ and the Arthritis Impact Measurement Scale, which have been carefully evaluated and shown to be comparable. ${ }^{23}$ They are measures of health status which assess the impact of arthritis on the quality of. life of the patient. The HAQ consists of 20 question selected from an original 62 questions designed th test all aspects of daily living. The HAQ disabilit $\mathbb{S}$ scale measures physical disability and social function but does not account for psychological disability Although large long term studies have yet to bQ performed using HAQ scores, it has been found tha for periods of longer than one year the HAQ score increases at a rate of $2 \%$ a year and is related to age and duration of disease. Such studies may be of lese value in addressing the issue of serious morbidity?

The functional classes of Steinbrocker et al have been widely used ${ }^{24}$ but are too insensitive to deteces changes over short periods of time. There was 
feeling at the consensus meeting that a morbidity index is needed which concentrates on serious, deleterious, long term effects of RA. Table 4 lists the most important aspects of this index. It would record the occurrence of events rheumatologists consider significant in the lives of patients with RA. They are not additive. It is impossible to know whether an ulcerating nodule is better or worse than an episode of scleritis or destruction of a major joint. To give a weighted morbidity score to patients, thereby deriving a 'numerical morbidity index', would be unhelpful. The only way to use such an assessment method is to record each event; by its very nature the presence of any the feature in the morbidity index suggest a poor outcome from RA. Two or more features suggest a very poor result. The construction of a morbidity index is a slow process. The suggestions in Table 4 represent an approach which, with further refinement, may lead to an acceptable and widely used index.

\section{Other measures}

No one doubts the importance of function to patients with RA. Indices such as the HAQ score have been evaluated exhaustively and this does not need repeating. This measure should be widely used, but should not be the final gold standard by which to judge the outcome of RA.

For many years radiological assessments have been at the forefront of outcome measures, but their practical importance is less clear. There was no support at the consensus meeting for the view that plain radiographs of the hands and feet scored by the methods of Larsen et $a l^{25}$ or Sharp et $a l^{26}$ should form the mainstay of measuring outcome. Indeed there was a feeling that the use of $x$ rays of small joints is of dubious advantage in determining either function or morbidity. Destruction of a major joint is more serious. Complete destruction of the hip or knee will have a marked detrimental effect. Debate about the true place of $x$ rays using current technology has subsided; there is now a relatively negative view of $x$ rays and less value is placed on them.

Death is the final outcome of disease, and evidence that RA leads to increased mortality is widely accepted. Even though the relative risk of dying from a variety of causes, varying from infections to cardiac diseases, is increased, ${ }^{27}$ however, the relative risk is no more than one and a half to three times normal. To detect the altered mortality of RA many patients must be studied for 10-20 years. This increased mortality is too insensitive a factor to use on its own; only a minority of patients with RA die from their disease.

Drug reactions are the final cause of a poor outcome in RA. Table 5 lists the types of serious side effects. Antirheumatic drugs lead to many side effects, though fortunately most of these are minor. Only severe or serious reactions need to be considered.

\section{Relation between measures}

The relations between measures can be looked at in two ways depending upon whether the RA is severe or mild. Patients with the most severe RA-that is, those who have persisting disease activity despite use of slow acting antirheumatic drugs, show the most severe functional declines. They will often have extra-articular features and destruction of major joints and may die prematurely. In mild RA none of these events may happen. The measures used are related but may act independently and should be recorded separately. A common fallacy is that a record of a multitude of different measures and the use of complex multivariate statistical analyses will give scientific gains. It has certainly been tried in large North American studies based on the HAQ score. ${ }^{3} 28$ The information gained, however, does not justify making major resources available for similar projects.

\section{Conclusions}

If one takes a widely used and intensively studied slow acting antirheumatic drug like injectable gold and asks how it should be used in RA, two things become clear. We all accept it is better than placebo treatment over 6-12 months, but we cannot agree on its overall effect on the disease. Is it very good over several years or is its action of marginal advantage over a limited period of time? Situnayake recently

Table 4 Morbidity assessment

\footnotetext{
Destruction of major joints-for example, hip, knee

Development of a major extra-articular complication-for example, ulcerating nodule, vasculitis leading to gangrene, severe scleritis

Inability to work

Loss of independence
}

\section{Table 5 Serious drug reactions}

Blood-thrombocytopenia, leucopenia, pancytopenia Dermatological-major rash, Stevens-Johnson syndrome Renal-proteinuria, renal failure

Gastrointestinal-bleeding ulcer, perforated ulcer Others-hepatic damage, infection 
reviewed the evidence for a 'disease modifying' effect of antirheumatic drugs ${ }^{29}$ and like others ${ }^{30}$ concluded that there is little evidence for a very long term effect. We may have poor drugs, poor measures, or both. There is a need to improve measurement of disease activity and outcome.

The consensus meeting felt present measures were inadequate, progress in assessing RA was slow, and changes were needed. Treatment with a drug like gold is usually part of a more general treatment policy. The commonest policy is to try continually to suppress disease activity and the high ESR of uncontrolled RA, keeping symptoms of synovitis limited with a variety of antirheumatic drugs.

Opinion differs as to what current measures examine. This is most noticeable with indices such as the HAQ score and the Arthritis Impact Measurement Scale. Their proponents would argue that these are true measures of outcome and that no other indices are needed. Although the consensus meeting did not wish to undermine the value of these indices, there was a unanimous view that they are limited in the information they collect, and most closely measure function. Other indices like the McMaster health index are aimed at the quality of life in rheumatoid disease and patients' abilities to cope with their arthritis. ${ }^{31}$ All of these measures ignore, at least in direct terms, typical clinical features such as destruction of a single joint or a serious extra-articular complication. Any assessment of disability should include the dimensions of chronic arthritis typically seen by rheumatologists and serious complications.

There were three principal recommendations from the consensus meeting: $(a)$ a simple, validated index is needed to assess response to slow acting antirheumatic drugs. Patients should be placed into several overall categories of response; $(b)$ morbidity must be measured in a standardised way; $(c)$ the relation of functional indices like $\mathrm{HAQ}$ to both indices of response and morbidity should be determined. We hope these recommendations will be considered, discussed, validated, and, if accepted, put into action. The time has passed when it is appropriate for rheumatologists to use drugs which have major potential risks without concrete evidence either that long term treatment with single drugs or, more generally, treatment policies are effective. We would welcome continuing debate on the subject. This could either be by private correspondence with the authors or, at the editor's discretion, within the Annals.

Participants in the consensus meeting have research studies in this area supported by the Arthritis and Rheumatism Council, the
Wellcome Trust, and the North East Thames regional research committee.

\section{References}

1 Huskisson E C. Anti-rheumatic drugs. Eastbourne: Praege® Scientific, 1983.

2 Scott D L, Symmons D P M, Coulton B L, Popert A J. Longterm outcome of treating rheumatoid arthritis. Results after $2 \Phi$ years. Lancet 1987; i: 1108-11.

3 Sherrer Y S, Block D A, Mitchell D M, Young D Y, Fries J Fש The development of disability in rheumatoid arthritis. Arthrit\$ Rheum 1986; 29: 494-500.

4 Rasker J J, Cosh J A. The natural history of RA. A 15 yea? follow-up study. Clin Rheumatol 1984; 3: 11-20.

5 Jennett B. High technology medicine: benefits and burden Oxford: Oxford University Press, 1986.

6 Jennett B, Gleave J, Wilson P. Brain death in three neurosuf gical units. $\mathrm{Br}$ Med $J$ 1981; 282: 533-9.

7 Gibson T, Clark B. Use of simple analgesics in rheumatoi arthritis. Ann Rheum Dis 1985; 44: 27-9.

8 Wright V, Amos R. Do drugs change the course of rheumatoid arthritis? $\mathrm{Br}$ Med J 1980; 280: 964-6.

9 Sharp J T. Radiographic evaluation in the course of articulas disease. Clin Rheum Dis 1983; 9: 541-57.

10 Ianuzzi L, Dawson N, Zein N, Kushner I. Does any therap slow radiographic deterioration in rheumatoid arthritis? $N$ Eng J Med 1983 309: 1027-9.

11 Scott D L, Grindulis K A, Struthers G R, Coulton B L, Popeణ A T, Bacon P A. Progression of radiological changes i rheumatoid arthritis. Ann Rheum Dis 1984; 43: 8-17.

12 Fries J F, Spitz P, Kraines R G, Holman H R. Measurement की patient outcome in arthritis. Arthritis Rheum 1980; 23: 137-45

13 Symmons D P M. Morbidity in rheumatoid arthritis. $\mathrm{Br}$ Rheumatol 1988; 27 (suppl 1): 44-54.

14 Mallya R K, Mace B E. The assessment of disease activity i⿱乛龰 rheumatoid arthritis using a multivariate analysis. Rheumartology and Rehabilitation 1981; 20: 14-17.

15 Lansbury J. Report of a three year study of the systemic and articular indices in rheumatoid arthritis: theoretical and clinicar considerations. Arthritis Rheum 1958; 1: 505-22.

16 Dawes P T, Fowler P D, Collins M, Shadforth M F. Evaluation of an inflammatory index of rheumatoid arthritis. $\mathrm{Br}$ Rheumatol 1986; 25: 206-9.

17 Kirwan J R, Reeback J S. Stanford health assessment questioø naire modified to assess disability in British patients with rheumatoid arthritis. Br J Rheumatol 1986; 25: 206-9.

18 Pinals R S, Masi A T, Larsen R A. Preliminary criteria foํำ remission in rheumatoid arthritis. Arthritis Rheum 1981; 24 1308-15.

19 Empire Rheumatism Council. Gold therapy in rheumatoi arthritis: report of a multicentre controlled trial. Ann Rheurer Dis 1960; 19: 95-119.

20 Multicentre trial group. Controlled trial of D-penicillamine i⿱ severe rheumatoid arthritis. Lancet 1973; i: 275-80.

21 Dixon J S, Hayes S, Constable P D L, Bird H A. What are the 'best' measurements for monitoring patients during short-term second-line therapy. Br J Rheumatol 1988; 27: 37-43.

22 Fries J F. Towards an understanding of patient outcome measurement. Arthritis Rheum 1983; 26: 697-704.

23 Meenan R F, Gertman P M, Mason J H. Measuring health status in arthritis. Arthritis Rheum 1980; 23: 146-52.

24 Steinbrocker O, Traeger C H, Battman R C. Therapeuti菏 criteria in rheumatoid arthritis. JAMA 1949; 140: 659-62.

25 Larsen A, Dale K, Eek M. Radiographic evaluation rheumatoid arthritis and related conditions by standard refer-

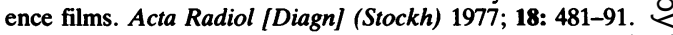

26 Sharp J T, Lidsky M D, Collins L C, Moreland J. Methods o

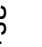

,

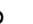

$$
\text { is }
$$
. 
scoring the progression of radiological changes in rheumatoid arthritis. Correlation of radiologic, clinical and laboratory abnormalities. Arthritis Rheum 1971; 14: 706-20.

27 Prior P, Symmons D P M, Scott D L, Brown R, Hawkins C E. Cause of death in rheumatoid arthritis. Br J Rheumatol 1984; 23: 92-9.

28 Sherrer Y S, Block D A, Mitchell D M, Roth S H, Wolfe F, Fries J F. Disability in rheumatoid patients: a comparison of prognosis factors across three populations. $J$ Rheumatol 1987; 14: 705-9.
29 Situnayake R D. Can 'disease modifying' drugs influence outcome in rheumatoid arthritis? Br J Rheumatol 1988; 27 (suppl 1): 55-64.

30 Pullar T, Capell H A. A rheumatological dilemma: Is it possible to modify the course of rheumatoid arthritis? Can we answer the question? Ann Rheum Dis 1985; 44: 134-40.

31 Chambers L W, Macdonald L A, Tugwell P, Buchanan W W, Kraag G. The McMaster Health Index Questionnaire as a measure of quality of life for patients with rheumatoid arthritis. $J$ Rheumatol 1982; 9: 780-4. 